\title{
ÚNG DỤNG KHOA HỌC CÔNG NGHỆ PHỤC VỤ QUẢN LÝ, SỬ DỤNG HIỆ QUẢ NGUỒN NƯỚC THEO THỜI GIAN THỤ'C
}

\author{
Nguyễn Quốc Hiệp ${ }^{1}$, Lê Văn Lập ${ }^{1}$, Nguyễn Anh Hùng ${ }^{1}$, Đỗ Hoài Nam¹
}

Tóm tắt: Trung tâm Công nghệ phần mềm Thủy lợi (Trung tâm) đã kế thì̀a kết quả nghiên cưu tù các đề tài, dụ án cấp Nhà nước, cấp Bộ về công nghệ thông tin, thiết bị tụ động hóa do Trung tâm chủ trì thực hiện để tích hợp và phát triển thành hệ thống hỗ trọ ra quyết định phuc vu quản lý, điều hành các công trình thưy lợi nhằm nâng cao hiệu quả sủ dụng nguồn nước, giảm thiểu thiệt hại do hạn hán, đáp úng yêu cầu sản xuất nông nghiệp và các ngành kinh tế khác. Hệ thống này được Trung tâm liên tục nâng cấp, cập nhật các công nghệ mới tiên tiến trên thế giới và xây dựng các chức năng nhằm đáp úng các yêu cầu của co quan quản lý cấp Trung ưong và địa phuơng trên phạm vi cả nước.

Từ khóa: Hệ thống giám sát hồ chứa, viễn thám, GIS.

Ban Biên tập nhận bài: 12/08/2019 Ngày phản biện xong: 15/09/2019 Ngày đăng bài: 25/10/2019

\section{1. Đặt vấn đề}

Hiện nay, nhu cầu sử dụng nước của các ngành kinh tế, xã hội đang tăng nhanh, nhất là nhu cầu nước cho sinh hoạt, sản xuất nông nghiệp, công nghiệp, nuôi trồng thuỷ sản và chăn nuôi. Trong khi nguồn tài nguyên nước ở Việt Nam nói chung và ở khu vực tỉnh Hà Tĩnh nói riêng có xu thế suy giảm nhanh cả về số lượng lẫn chất lượng. Về lượng, do tác động của BĐKH, tổng lượng mưa hàng năm được dự báo tăng nhẹ, nhưng tập trung phần lớn vào mùa mưa. Ngược lại, mùa khô được dự báo sẽ khô cạn hơn.

Mặc dù trên địa bàn tỉnh Hà Tĩnh đã được đầu tư xây dựng nhiều công trình thủy lợi có nhiệm vụ điều tiết dòng chảy và cấp nước, nhưng các công trình chủ yếu vận hành riêng biệt, thiếu tính hệ thống. Bên cạnh đó, do thiếu thông tin, dữ liệu về lượng mưa và dòng chảy đến nên công tác vận hành công trình đảm cấp nước và phòng lũ còn gặp nhiều khó khăn. Do vậy, một hệ thống hỗ trợ ra quyết định quản lý, điều hành các công

${ }^{1}$ Trung tâm Công nghệ phần mềm Thủy lợ - Viện Khoa hoc Thủy lợi Việt Nam

Email:nguyenquochiep@cwrs-au.vn trình thủy lợi nhằm phục vụ việc nâng cao hiệu quả khai thác nguồn nước.

Bài báo trình bày kết quả xây dựng hệ thống thông tin quản lý, sử dụng hiệu quả tài nguyên nước (mùa khô) theo thời gian thực áp dụng cho tỉnh Hà Tĩnh. Hệ thống bao gồm các hợp phần về thiết bị giám sát, điều khiển; dữ liệu viễn thám; lưu trữ dữ liệu lớn; và phần mềm vận hành hệ thống để hỗ trợ các đơn vị quản lý ra quyết định vận hành các công trình thủy lợi một cách tốt nhất.

\section{Phương pháp nghiên cứu}

\subsection{Giới thiệu khu vục nghiên cứu}

Hà Tĩnh là một tỉnh thuộc khu vực Bắc Trung Bộ, với diện tích tự nhiên $6.000 \mathrm{~km}^{2}$ (Hình 1). Do đặc thù về vị trí địa lý và địa hình, Hà Tĩnh thường xuyên chịu ảnh hưởng của thiên tai được dự báo thuộc nhóm các tỉnh thành chịu tác động tiêu cực bởi biến đổi khí hậu. Trong những thập kỷ gần đây, các hiện tượng thời tiết cực đoan như bão, mưa lớn gây lũ, ngập lụt và lũ quét trên địa bàn tỉnh có xu hướng gia tăng cả về tần suất và cường độ, đặc biệt tình hình hạn hán, thiếu nước trong mùa khô ngày càng trở nên nghiêm trọng. Trong bối cảnh đó, rất cần thiết phải nghiên cứu 


\section{BÀI BÁO KHOA HỌC}

ứng dụng các công nghệ mới để xây dựng hệ thống thông tin quản lý, vận hành hệ thống công (mùa khô) theo thời gian thực nhằm ứng phó với biến đổi khí hậu ở tỉnh Hà Tĩnh nói riêng và khả trình thủy lợi sử dụng hiệu quả tài nguyên nước năng nhân rộng trong khu vực nói chung.

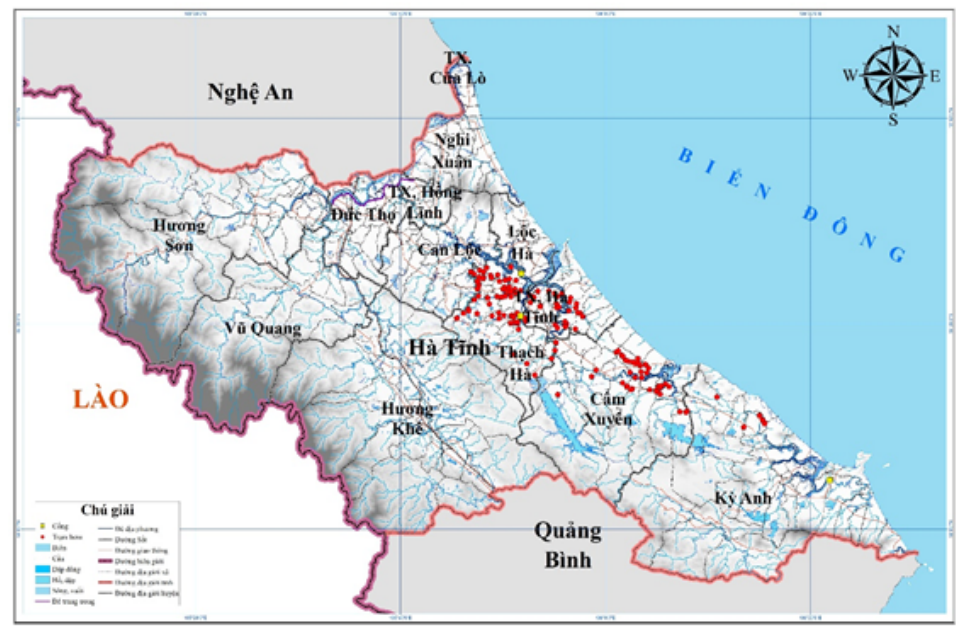

Hình 1. Bản đồ vị trí địa lý tỉnh Hà Tinh và phân bố các công trình thủy lợi (chấm đỏ)

\subsection{Sơ đồ nghiên cúu công nghệ}

a) Phưong pháp tiếp cận

Nghiên cứu đã kế thừa các thành tựu nghiên cứu về công nghệ thông tin trên thế giới, sử dụng các phần mềm mã nguồn mở, thư viện tương tác bản đồ Openlayer, thư viện tạo ảnh bản đồ MapServer, cơ sở dữ liệu PostgreSQL, v.v... để xây dựng phần mềm vận hành hệ thống giám sát.

b) So đồ nguyên lý công nghệ

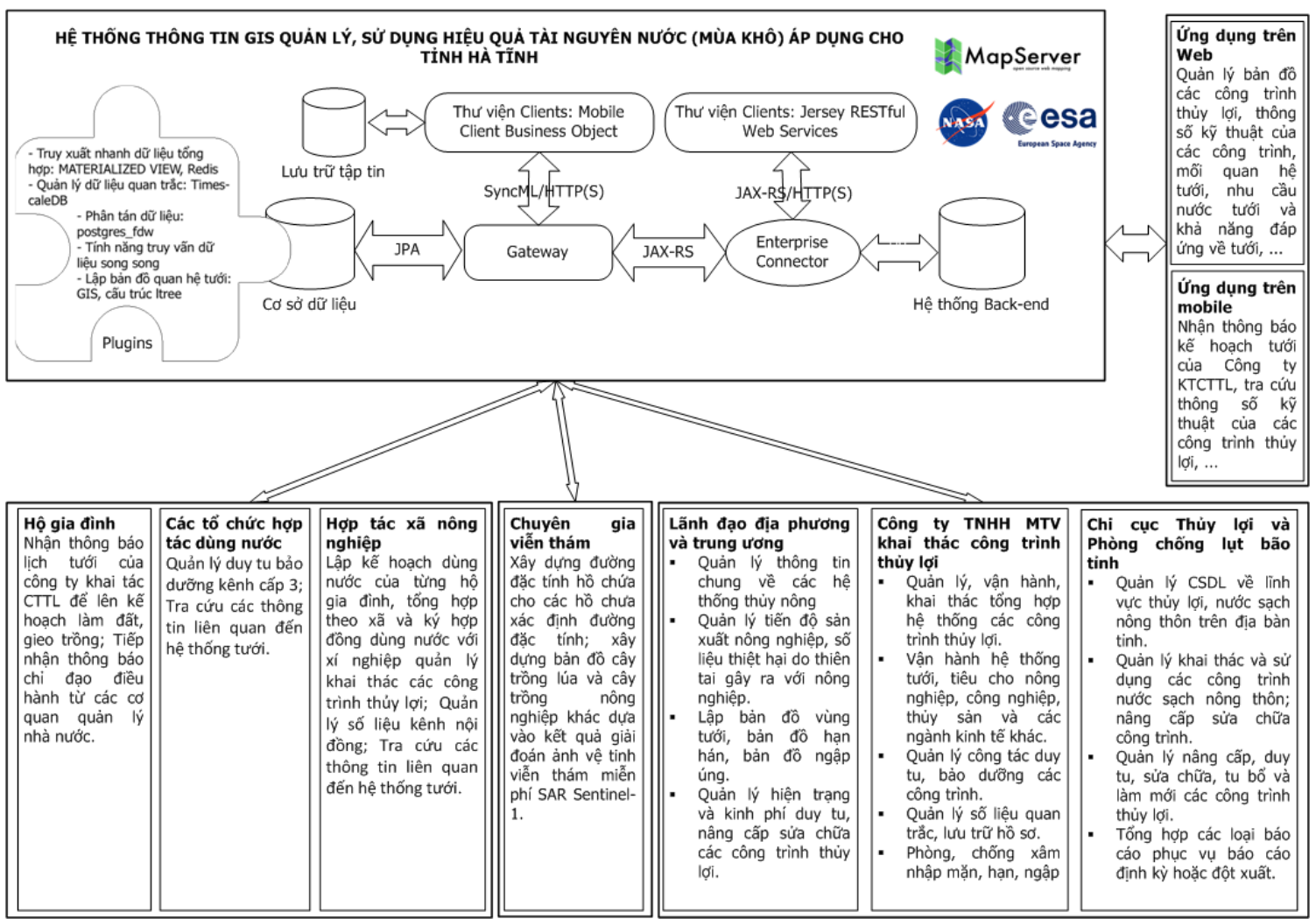

Hình 2. So đổ tổng thể hệ thống thông tin quản lý, sủ dụng hiệu quả tài nguyên nước (mùa khô) theo thời gian thực áp dụng cho tỉnh Hà Tình 


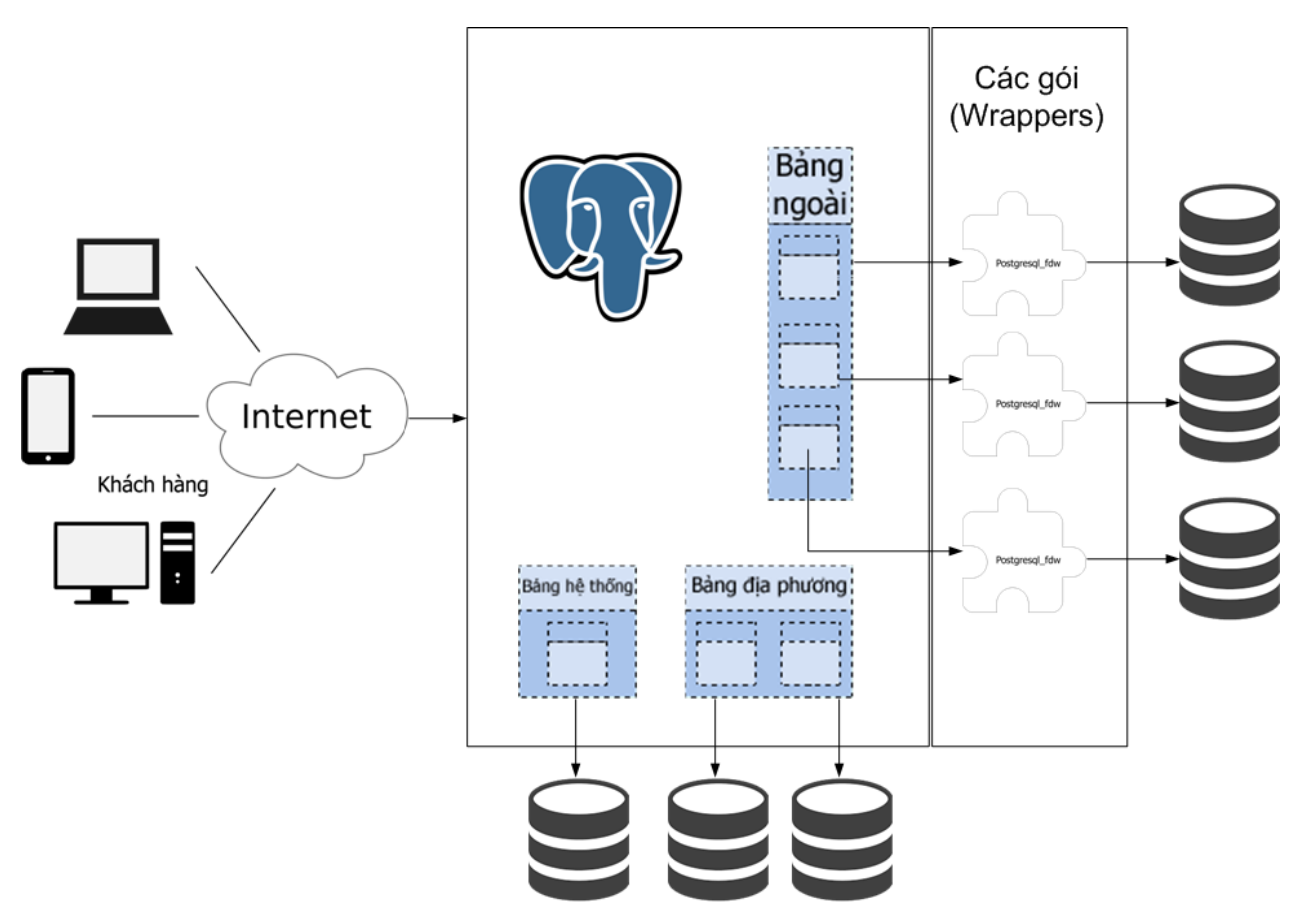

Hình 3. Mô hình quản lý co sở dĩ liệu hệ thống tuoói phân tán theo tỉnh

Mô-đun quản lý số liệu quan trắc

Hệ thống thiết bị giám sát, điều khiển của hệ thống bao gồm: Thiết bị thu thập, lưu trữ và truyền số liệu từ xa (thiết bị RTU); Thiết bị đo lượng mưa, mực nước; Thiết bị đo độ mở tràn, cống, v.v... Số liệu quan trắc được gửi về máy chủ dữ liệu gồm các thông số cơ bản như mã hiệu, loại thông số của trạm đo, mã hiệu của công trình quản lý được quan trắc, số liệu quan trắc, ngày giờ. Mỗi số liệu quan trắc đều phải có thời gian đo có đơn vị thời gian là giây. Số liệu quan trắc được lưu trữ trong các bảng dữ liệu ngày càng nhiều theo thời gian và làm giảm tốc độ truy vấn dữ liệu mỗi khi muốn tra cứu số liệu của một trạm đo trong một khoảng thời gian bất kỳ hoặc phân tích số liệu quan trắc để tìm kiếm quy luật. Với nhu cầu như vậy, hệ quản trị cơ sở dữ liệu chuỗi thời gian ra đời. Nghiên cứu này sử dụng hỗ trợ timescaleDB là một mở rộng của PostgreSQL. Cơ sở dữ liệu timescaleDB chạy bên trong thể hiện PostgreSQL. Nó tối ưu cấu trúc lưu bằng cách chia lát bảng thành các bảng đơn gọi là hypertables.

\section{Mô-đun dũ liệu viễn thám}

Các loại ảnh viễn thám trước đây phải mua với giá rất cao, tuy nhiên từ năm 2015 trở lại đây đã có nguồn ảnh Sentinel miễn phí có độ phân giải cao là $10 \mathrm{~m}$, được cung cấp bởi ESA - Cơ quan vũ trụ châu Âu. Chương trình Sentinel tập trung vào quan sát trái đất, khí quyển, đại dương và giám sát đất đai. Hiện tại hai vệ tinh Sentinel$1 \mathrm{~A}$ và Sentinel-1B đã cung cấp ảnh radar là loại ảnh không bị ảnh hưởng bởi mây mù và mưa bão với tần suất 6 ngày có một ảnh và vệ tinh Sentinel-2 cung cấp ảnh quang học với tần suất 12 ngày có một ảnh. Việc này đã giải quyết được những khó khăn của các đề tài, dự án triển khai ở Việt Nam. Với nguồn ảnh trên Trung tâm đã phát triển một hệ thống thuật toán cho phép xây dựng một bộ công cụ phân tích ảnh viễn thám tự động, xây dựng bộ công cụ phân tích ảnh Sentinel phục vụ giải quyết các vấn đề như xác định đường đặc tính lòng hồ chứa để phục vụ kiểm đếm nguồn nước; xác định diện tích cây lúa và diễn biến gieo trồng để phục vụ cho việc tính toán nhu cầu tưới, dự báo năng suất và sản lượng cây lúa.

\section{Mô-đun luu trũ dĩ liệu lớn}

Các số liệu trên được lưu trữ trên phạm vi cả nước, trong nhiều năm và là trung tâm dữ liệu 
cho các đơn vị khai thác sau này. Trung tâm đã nghiên cứu để xây dựng một mô hình đảm bảo an toàn về mặt dữ liệu, tốc độ truy vấn nhanh. Mô hình cơ sở dữ liệu lớn (Hình 3) như sau:

Hệ thống chia thành ba khối chính như sau:

- Các bảng hệ thống: đây là các bảng mặc định của hệ thống, cung cấp chức năng tổng hợp các bảng có trong cơ sở dữ liệu, các trường và thông tin chi tiết của mỗi trường thuộc bảng dữ liệu tra cứu, xác định tên khóa chính của bảng,... Các tính năng này giúp xây dựng thư viện lập trình động cho các chức năng của hệ thống tưới.

- Các bảng địa phương: đây là các bảng cơ sở dữ liệu của hệ thống tưới. Đối với các bảng có dữ liệu lớn, ví dụ dữ liệu bản đồ, thì các bảng này sẽ được lưu trữ phân tán ra các bảng ngoài nằm ở các máy chủ khác nhau dựa trên gói postgres_fdw.

- Các bảng ngoài: các bảng này chứa thông tin như tài khoản truy cập vào máy chủ chứa bảng dữ liệu, tên bảng được ánh xạ đến. Mô hình cha con này có thể hiểu là các bảng dữ liệu con (bảng ngoài) có các trường thuộc tính giống với bảng dữ liệu cha (bảng bị chia dữ liệu). Khi truy vấn dữ liệu từ bảng cha thì postgres_fdw sẽ tự động truy vấn dữ liệu của tất cả các bảng con và dữ liệu có trong bảng cha, sau đó ghép kết quả trả về cho người dùng.

Ngoài ra hệ thống tưới còn được tích hợp dịch vụ File Server được phát triển dựa trên dự án Netty nguồn mở. Netty là một thư viện nền tảng dựa trên cấu trúc khách chủ vào/ra không chặn để phát triển các ứng dụng mạng như giao thức giữa máy chủ và máy khách. Nền tảng ứng dụng mạng hướng sự kiện và các công cụ xử lý không đồng bộ được sử dụng để đơn giản hóa việc lập trình mạng như TCP và UDP. Dịch vụ File Server giúp tổ chức lưu trữ các loại tập tin khác nhau của hệ thống bao gồm bản đồ, ảnh vệ tinh và các tập tin văn bản khác.

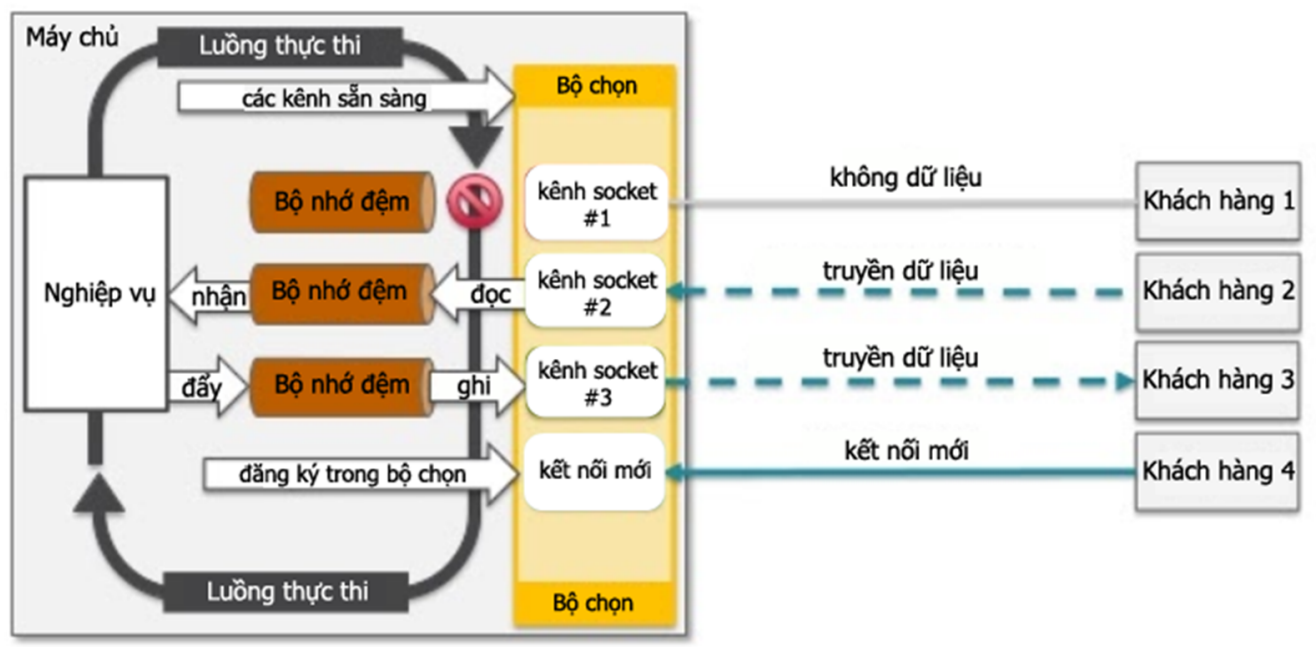

Hình 4. Co chế hoạt động của Netty

\section{Mô-đun GIS}

Hiện nay, sử dụng thiết bị di động và bản đồ số (GIS) để điều hành công việc đang là xu thế trên thế giới và ở Việt Nam, vì vậy Trung tâm đã sử dụng nền tảng công nghệ WebGIS để xây dựng và phát triển phần mềm. Công nghệ $\mathrm{We}$ bGIS hiện nay có hai xu hướng để phát triển phần mềm. Xu hướng thứ nhất: sử dụng công nghệ mã nguồn đóng của hãng ESRI để phát triển, ưu điểm của xu thế này là xây dựng, phát triển phần mềm đơn giản do sử dụng các công cụ có sẵn, nhược điểm: cần phải mua bản quyền với giá tương đối cao (khoảng 600 triệu đồng cho một bản quyền). Xu thế thứ hai: Sử dụng mã nguồn mở của Hiệp hội phát triển mã nguồn mở, ưu điểm của xu thế này là không phải mất chi phí mua bản quyền phần mềm, nhược điểm là cần phải nghiên cứu mã nguồn để tích hợp và 
phát triển phần mềm. Để chủ động cho việc phát triển, triển khai phần mềm vào thực tế sau này và hiện tại không phải mua bản quyền, Trung tâm đã chọn cách tiếp cận phát triển phần mềm là sử dụng mã nguồn mở OpenLayers và MapServer.

\section{Kết quả và thảo luận}

a) Chuẩn bị dũ liệu đầu vào

Gồm có dữ liệu tĩnh và dữ liệu động. Dữ liệu động là dữ liệu thường xuyên được cập nhật, dữ liệu tĩnh là dữ liệu ít khi thay đổi.

Dữ liệu động của hệ thống tưới cho tỉnh Hà Tĩnh gồm có các loại dữ liệu sau:

- Ảnh viễn thám: Tự động giải đoán ảnh viễn thám Sentinel (12 ngày có 1 ảnh) để cập nhật diện tích trồng lúa, diện tích cây hoa mầu;

- Số liệu mưa, khí tượng: nguồn dữ liệu từ hệ thống quan trắc, dữ liệu dự báo từ một hệ thống dự báo khí tượng hoặc dữ liệu khí tượng từ kịch bản biến đổi khí hậu;

- Hệ thống giám sát nguồn nước: giám sát mực nước hồ, độ mở cống, mực nước kênh sau cống,... Dữ liệu này có thể nhận từ các thiết bị quan trắc tự động hoặc người dùng có thể nhập liệu thủ công phục vụ cho việc quản lý lượng nước đến và ra khỏi hồ.

Dữ liệu tĩnh của hệ thống tưới cho tỉnh Hà Tĩnh gồm có các loại dữ liệu sau:

- Các hộ dùng nước: là danh sách các tổ chức sử dụng nước cho nông nghiệp và các ngành kinh tế khác như nước cho sinh hoạt, công nghiệp, nuôi trồng thủy sản,...

- Các công trình thủy lợi: Số hóa hiện trạng các công trình thủy lợi trên bản đồ.

- Bản đồ thửa đất: Thông tin bản đồ thửa đất (số tờ, số thửa) do Sở tài nguyên và môi trường tỉnh quản lý.

\section{b) Kết quả đầu ra}

Chức năng quản lý tình hình sản xuất, xác định chi phí của dịch vu tuới cho các hộ dùng nước:

- Cho phép xác định diện tích cần phục vụ tưới trên bản đồ WebGIS: Công ty Khai thác công trình thủy lợi (KTCTTL) và đơn vị sử dụng nước thống nhất để xác nhận diện tích cần phục vụ tưới theo biện pháp, cơ cấu tưới tiêu của từng vụ trên nền bản đồ GIS. Khi hai bên đã xác nhận thì một bên không có quyền thay đổi.

- Cho phép theo dõi diện tích và cơ cấu cây trồng: Sử dụng công nghệ ảnh viễn thám Sentinel-2 (12 ngày có 1 ảnh) để tự động tổng hợp báo cáo diện tích trồng lúa, diện tích cây hoa mầu theo từng đơn vị sử dụng nước, theo chi nhánh KTCTTL, theo công ty KTCTTL và theo toàn tỉnh. Diện tích các loại cây trồng được hiển thị trên nền bản đồ bằng các mầu sắc khác nhau (hình 05).

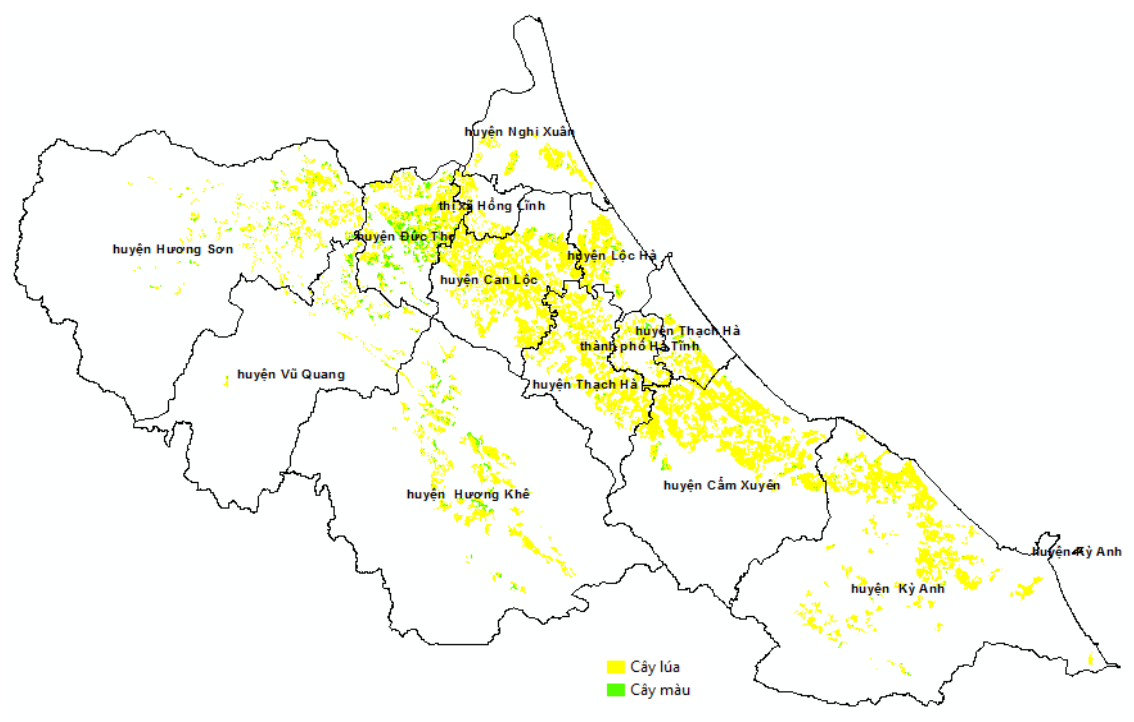

Hình 5. Lớp bản đồ phân bố cây trồng lúa và cây trồng màu năm 2018 
- Cho phép xác định đường đặc tính lòng hồ chứa trên địa bàn tỉnh Hà Tĩnh với các bước (i) tiền xử lý ảnh Sentinel-1; (ii) xây dựng thuật toán giải đoán ảnh nhằm tự động hóa quá trình xác định diện tích mặt hồ trên cơ sở sử dụng các điểm tán xạ ngược của các phân cực ảnh radar trên nền đất khô, đất ẩm và đất ngập nước; (iii) loại bỏ nhiễu và chữa giá trị các điểm ảnh là nước nhưng được giải đoán không phải là nước và ngược lại; (iv) các phương pháp kiểm chứng kết quả giải đoán đường đặc tính hồ chứa:

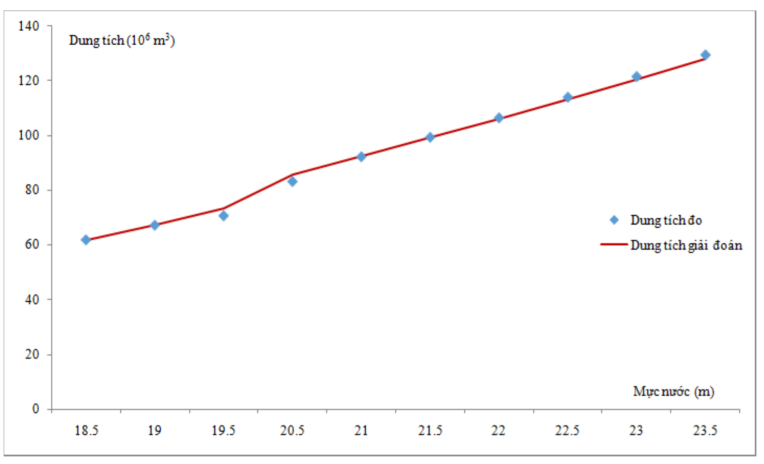

Hình 6. Đồ thị so sánh đường $Z \sim W$ giũua đo thực tế và giải đoán tù ảnh Sentinel-1 của hồ

\section{Sông Rác}

Chức năng hỗ trọ các cấp quản lý điều hành các hệ thống tưới

Tính toán nhu cầu tưới, kiểm đếm nguồn nước của các hệ thống tưới nhằm hỗ trợ lập kế hoạch dùng nước, điều chỉnh cơ cấu cây trồng cho phù hợp với điều kiện thực tế, cảnh báo hạn hán. Hình 08 là thiết bị trạm đo mực nước hồ kết hợp đo mưa tự động được lắp đặt tại hồ chứa nước Thượng Sông Trí - Tỉnh Hà Tĩnh phục vụ việc kiểm đếm nguồn nước.

Chức năng quản lý công trình thủy lợi phương pháp đi thực địa xác định ranh giới mặt nước bằng GPS, phương pháp so sánh giá trị dung tích hồ được xác định dựa trên đường đặc tính của hồ với giá trị dung tích hồ được giải đoán từ ảnh từ đó xác định sai số giải đoán và phương pháp chồng xếp kết quả giải đoán với ảnh quang học có độ phân giải siêu cao tại cùng thời điểm. Hình 6,7 là đồ thị so sánh đường $\mathrm{Z}$ W giữa đo thực tế và giải đoán từ ảnh Sentinel1 của hồ Sông Rác và hồ Kẻ Gỗ.

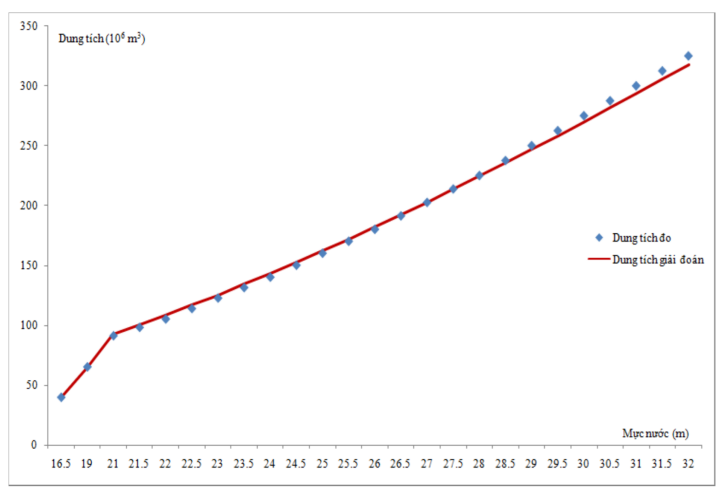

Hình 7. Đồ thị so sánh đưòng $Z \sim W$ giũa đo thực tế và giải đoán tù ảnh Sentinel-1 của hồ $K e ̉$ Gồ

Quản lý toàn bộ hệ thống kênh và công trình trên kênh, diện tích tưới phụ trách của các cấp kênh của các hệ thống tưới trên nền bản đồ GIS nhằm tạo thành cơ sở dữ liệu về các công trình thủy lợi phục vụ công tác quản lý tài sản, sửa chữa nâng cấp hệ thống, nghiên cứu khoa học, quy hoạch,... Hình 09 là giao diện phần mềm quản lý, sử dụng hiệu quả tài nguyên nước (mùa khô) theo thời gian thực áp dụng cho tỉnh Hà Tĩnh.
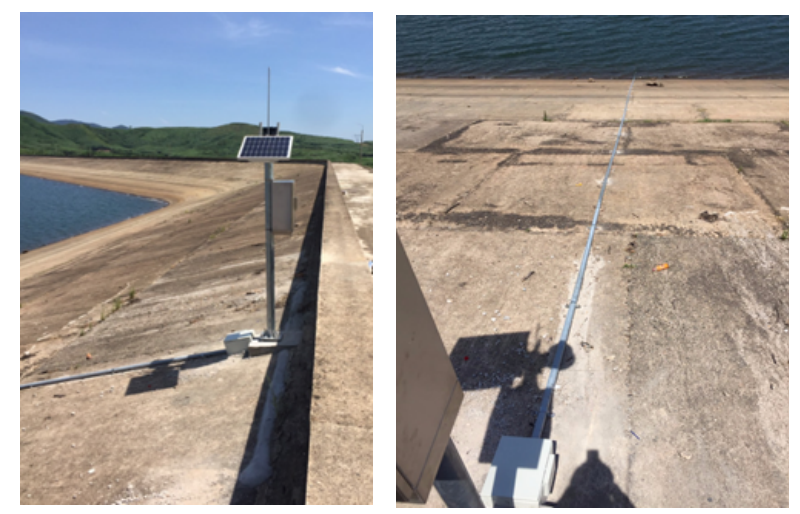

Hình 8. Trạm đo mục nước hồ kết hợp đo mua được lắp đặt tại hồ chưa nước

Thuợng Sông Trí - tỉnh Hà Tĩnh 


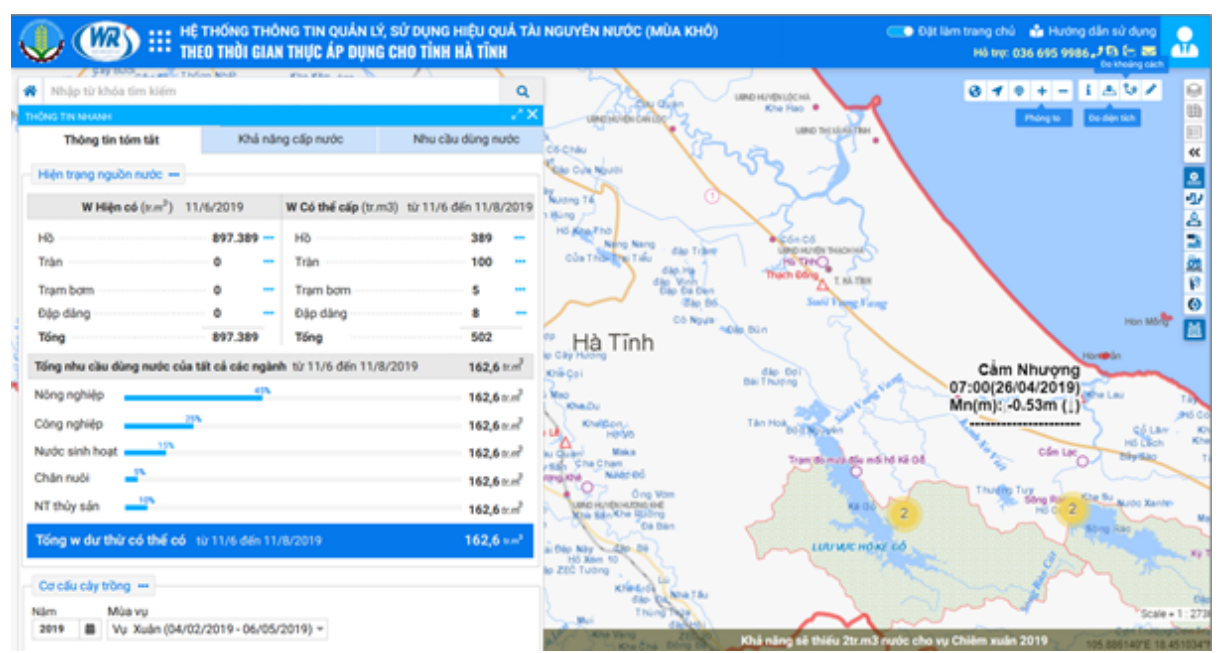

Hình 9. Giao diện phần mềm quản lý, sủ dụng hiệu quả tài nguyên nuớc (mùa khô) theo thời gian thực áp dụng cho tỉnh Hà Tïnh

\begin{tabular}{|c|c|c|c|c|c|}
\hline QUẢN LÝ DỮ LIỆU & & LẬP KE HOẠCH TƯớl & VẬN HȦNH & BÁO CÁO THÓNG KÊ & QUẢN TR!̣ HỆ THONG \\
\hline 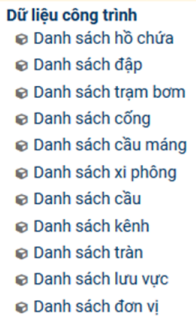 & 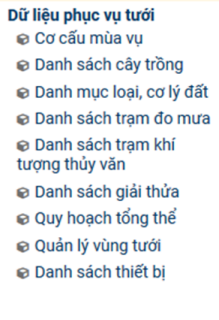 & $\begin{array}{l}\text { Dữ liệu mưa } \\
\text { voư liệu khi tượng thủy } \\
\text { văn } \\
\text { - Tiến độ sản xuất } \\
\text { Lập kế hoạch tưới } \\
\text { Bố trí cây trồng } \\
\text { Lập kế hoạch tưới test }\end{array}$ & $\begin{array}{l}\text { Điều khiển vận hành thực tế } \\
\text { @ Vận hành hệ thống tưới }\end{array}$ & 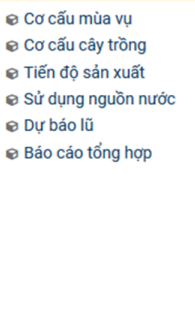 & $\begin{array}{l}\text { @ấu hình hệ thống } \\
\text { Quán lý đơn vị sử dụng } \\
\text { Quản lý nhóm quyền } \\
\text { Quản lý người dùng } \\
\text { Quản lý danh mục } \\
\text { Quản lý biểu mẫu } \\
\text { Quản lý lưới dữ liệu } \\
\text { Quản lý menu } \\
\text { Quán lý khung CSDL }\end{array}$ \\
\hline
\end{tabular}

Hình 10. Trình thực đơn các chức năng của hệ thống tưới Hà Tĩnh

\section{Kết luận}

Việc ứng dụng khoa học công nghệ để tạo ra công cụ hỗ trợ ra quyết định phục vụ quản lý, điều hành các công trình thủy lợi (theo xu hướng cuộc cách mạng công nghiệp lần thứ tư) do Trung tâm Công nghệ phần mềm Thủy lợi thực hiện được áp dụng vào thực tế đã bước đầu phát huy hiệu quả, giúp cho các đơn vị quản lý có thể nắm được các thông tin về vận hành, các thông tin về cảnh báo, dự báo một cách nhanh chóng để đưa ra các quyết định vận hành các công trình thủy lợi.

Với những kết quả đạt được từ thực tế triển khai hoàn toàn có cơ sở để khẳng định việc ứng dụng khoa học công nghệ đã và đang nâng cao hiệu quả sử dụng nguồn nước, giảm thiểu thiệt hại do hạn hán, đáp ứng yêu cầu sản xuất nông nghiệp và các ngành kinh tế khác tại các địa phương đã áp dụng. Do vậy công cụ hỗ trợ ra quyết định phục vụ quản lý, điều hành các công trình thủy lợi nên được khuyến khích để dần từng bước được sử dụng trên phạm vi toàn quốc.

Lời cảm ơn: Bài báo này là sản phẩm của đề tài "Nghiên cứu ứng dụng các công nghệ mới (viễn thám, WEBGIS và Tụ động hóa) xây dụng hệ thống thông tin quản lý, sủ dụng hiệu quả tài nguyên nước (mùa khô) theo thời gian thực nhằm ứng phó với biến đổi khí hậu, áp dụng cho tỉnh Hà Tĩnh", mã số BĐKH.17/16-20 thuộc Chuơng trình Khoa học và công nghệ úng phó với biến đổi khí hậu, quản lý tài nguyên và môi trương giai đoạn 2016-2020. Tập thể tác giả chân thành cảm ơn Chuoong trình đã tạo điều kiện để nhóm tác giả hoàn thành bài báo này. 


\title{
BÀI BÁO KHOA HỌC
}

\section{Tài liệu tham khảo}

1. Nguyễn Quốc Hiệp (2017), Nghiên cưu xây dựng hệ thống quản lý và hỗ trợ điều hành hệ thống tưới theo thời gian thực, Luận án tiến sỹ kỹ thuật, Viện Khoa học Thủy lợi Việt Nam, 57-59;

2. Nguyễn Quốc Hiệp, Nguyễn Anh Hùng (2019), Cách tiếp cận mới xây dụng đuoờng đặc tính hồ chứa bằng việc sử dụng ảnh viến thám radar sentinel-1, Tạp chí khí tượng thủy văn (số tháng 10 năm 2019), 11-18;

3. Module an toàn đập, hồ chứa, hệ thống cơ sở dữ liệu ngành thủy lợi http://thuyloivietnam.vn.

\section{APPLY SCIENCE AND TECHNOLOGY TO MANAGE AND EFFEC- TIVELY USE WATER RESOURCES IN REAL TIME}

\author{
Nguyen Quoc Hiep', Le Van Lap ${ }^{1}$, Nguyen Anh Hung ${ }^{1}$, Do Hoai Nam¹ \\ ${ }^{1}$ Center for Water Resources Software - Vietnam Acadamy for Water Resources
}

\begin{abstract}
Center for Water Resources Software (the Center) has inherited research results from State and ministerial-level studies, projects on information technology and automation equipment chaired by the Center to integrate and develop a decision support system for the management and administration of irrigation works, which aims to improve water use efficiency, to minimize drought damage and to meet production requirements of agriculture and other economic sectors. This system is continuously upgraded and updated with new advanced technologies in the world and developed functions to meet the requirements of Central and local management units throughout the country.
\end{abstract}

Keywords: Reservoir monitoring system, Remote sensing, GIS. 